\title{
La place et la parole des hommes féministes dans les réseaux sociaux numériques au Brésil
}

The Place and Presence of Feminist Men in Brazilian Social Networks

Mónica Graciela Zoppi Fontana and Sheila Elias de Oliveira

\section{OpenEdition}

1 Journals

Electronic version

URL: http://journals.openedition.org/aad/2356

DOI: $10.4000 /$ aad. 2356

ISSN: 1565-8961

Publisher

Université de Tel-Aviv

\section{Electronic reference}

Mónica Graciela Zoppi Fontana and Sheila Elias de Oliveira, « La place et la parole des hommes féministes dans les réseaux sociaux numériques au Brésil », Argumentation et Analyse du Discours [Online], 18 | 2017, Online since 15 April 2017, connection on 23 September 2019. URL : http:// journals.openedition.org/aad/2356 ; DOI : 10.4000/aad.2356

\section{This text was automatically generated on 23 September 2019}

\section{c) (7) $(9)$}

Argumentation \& analyse du discours est mis à disposition selon les termes de la licence Creative Commons Attribution - Pas d'Utilisation Commerciale - Pas de Modification 4.0 International. 


\section{La place et la parole des hommes féministes dans les réseaux sociaux numériques au Brésil}

The Place and Presence of Feminist Men in Brazilian Social Networks

Mónica Graciela Zoppi Fontana and Sheila Elias de Oliveira

\section{Introduction}

1 La présence d'hommes dans les manifestations féministes urbaines est fréquente. Cette présence est diffusée par les médias et surtout dans la circulation des photos et de posts dans les réseaux sociaux numériques. Des blogs dont les auteurs s'identifient comme hommes féministes/pro-féminisme se multiplient et produisent des effets polémiques sur les blogs féministes. La controverse est centrée sur la légitimité politique de la militance féministe des hommes.

2 Le droit à la parole est une question importante dans les études académiques qui se présentent comme féministes, et qui de ce fait défendent l'égalité des femmes et des hommes, notamment sur le plan des droits. Nous nous proposons de discuter ce pouvoir-parler à partir d'un fait courant dans les énonciations féministes ou présentées comme favorables au(x) féminisme(s) aujourd'hui : le questionnement du droit à la parole féministe exercée par un homme. Un homme peut-il se dire féministe ? Peut-on dire d'un homme qu'il est féministe? Ce ne sont pas des questions nouvelles à 1 'intérieur du mouvement. Nous souhaitons cependant réfléchir ici aux enjeux énonciatifs et discursifs qui sont en œuvre dans la prise de parole des hommes en tant que féministes dans les réseaux sociaux.

3 Il faut considérer les conditions socio-historiques qui déterminent le droit à la parole à partir d'un certain lieu d'énonciation. En effet, quand on parle, on ne le fait jamais sans être inscrit dans un lieu socialement autorisé - on parle en tant que femme, médecin, ami, etc. Prendre la place de locuteur-féministe suppose alors d'être socialement 
autorisé à parler depuis ce lieu, et, dans ce cas-là, l'autorisation doit être issue du féminisme en tant que mouvement collectif. Mais le féminisme, bien évidemment, n'est pas homogène, ce qui divise toujours les droits à la parole.

4 La question du droit à la parole féministe et de la reconnaissance d'une collectivité féministe se renouvelle dans le(s) mouvement(s). En France, la philosophe féministe Rosi Braidotti évoquait en 1983 la nécessité d'un renouveau du féminisme - un «féminisme critique ». Le noyau de cette nécessité était la mise en cause du lieu de parole du féminisme; elle remettait en question le sens de l'énoncé «nous sommes unes", dont elle essayait de trancher l'évidence à partir de la constatation des différents sujets féministes qui peuvent y être inclus.

5 L'hétérogénéité du nous se complexifie avec la tentative de prise de parole par les hommes comme locuteurs légitimes du féminisme. La question de la mixité/non-mixité hommes-femmes dans le mouvement féministe n'est pas nouvelle non plus et divise les féminismes jusqu'à présent. L'ouvrage Les hommes dans les mouvements féministes: sociohistoire d'un engagement improbable du sociologue Alban Jacquemart (2015) met en évidence la présence de cette discussion dans les mouvements féministes en France depuis les années 1970. Et dans les années 1980/1990, il constate la présence de travaux en France, à la suite des États-Unis, " qui se donnent pour objectif d'interroger la possibilité ou l'impossibilité de l'appropriation de la critique féministe par les hommes et/ou de prescrire les "bonnes" modalités de participation pour les hommes " (Jacquemart $2015: 18$ ).

6 La construction discursive d'un lieu d'énonciation pour les hommes dans les féminismes au Brésil est l'objet de notre étude. L'analyse est centrée d'abord sur les entrées machismo (" machisme »), feminismo ( féminisme »), feminista (" féministe ») et machista («machiste») dans des dictionnaires brésiliens, ce qui nous permet d'examiner les dissymétries dans le fonctionnement de ces paires lexicales d'antonymes dans la langue. Ensuite, on envisage des communautés Facebook qui se présentent comme créées par des hommes féministes, où nous nous proposons d'examiner les effets de sens produits par les procédures de désignation mises en œuvre pour légitimer leur position.

\section{Le mot et ses fonctionnements dans la langue}

7 Le fonctionnement morpho-sémantique du mot feminista en brésilien est similaire à celui de féministe en français. Le mot peut opérer comme substantif ou comme adjectif. En tant qu'adjectif, il sert aux deux genres morphologiques et il peut être référé à des objets animés ou inanimés : um programa feminista " un programme féministe » / uma jovem feminista " une jeune fille féministe ». Mais cette condition morpho-sémantique n'est pas suffisante pour assurer l'acceptation de la désignation um homem feminista " un homme féministe ", qui constitue notre objet ici.

8

Dans les dictionnaires français comme brésiliens, la description de l'usage de féministe/ feminista par rapport au genre n'est pas univoque ; la plupart des ouvrages évitent d'en donner des exemples, ou donnent des exemples où le mot ne se réfère pas à l'humain. Dans la définition du Larousse de la Langue Française (édition en ligne) l'hyperonyme "partisan" se réfère à l'humain, représentant une prétendue neutralité morphologique: "Relatif au féminisme; partisan du féminisme " ${ }^{1}$. La prétendue neutralité ne permet pas de percevoir la polémique inscrite dans le mot. Dans une autre 
direction, sans prétention de neutralité, le Trésor de la Langue Française Informatisé présente, sous la rubrique adjectif/substantif de l'entrée, la définition « (celui ou celle) qui se réclame du féminisme » suivie de l'exemple « un féministe convaincu $~^{2}$. L'entrée $\mathrm{du}$ Trésor évoque l'auto-identification pour prédiquer un sujet masculin comme féministe: "celui ou celle qui se réclame» du féminisme. L'adjectif convaincu dans l'exemple indique aussi l'instabilité de féministe quand employé par rapport à un sujet masculin; ce n'est pas un féministe, sans plus, c'est un féministe « convaincu » de sa condition.

Dans l'un des plus récents dictionnaires brésiliens du portugais (première édition 2001), le Dicionário Houaiss da Língua Portuguesa (édition en ligne), on trouve deux définitions, divisées par classe grammaticale: "adjetivo de dois gêneros (1909) - relativo ou pertencente ao feminismo (libelo f.) (adjectif à deux genres (1909) - relatif ou appartenant au féminisme ( contestation $f$. )) » et « adjetivo e substantivo de dois gêneros - sequaz do feminismo (militante $f$. ) (um grupo de f. inflamadas iniciou uma passeata ) (adjectif et substantif à deux genres - disciple du féminisme «militant $(e) f$.) ‘un groupe de f. enflammées a coordonné une marches » ${ }^{3}$. Dans ces définitions, l'effet de neutralité est dominant: les hyperonymes sequaz et pertencente n'ont pas de genre marqué, comme militante, employé dans l'exemple; l'hyperonyme relativo, comme partisan chez Larousse, se sert du masculin prétendu neutre. Mais cet effet est coupé dans l'exemple, où le sujet féministe porte la marque morphologique de genre avec l'adjectif inflamadas (« enflammées »).

10 Les lexicographes, comme on l'a vu chez Larousse et chez Houaiss, semblent en général ne pas être à l'aise pour considérer que feminista / féministe est une qualité ou une désignation des femmes, même si la plupart n'osent pas l'attribuer directement aux hommes - avec quelques exceptions, comme le Trésor français. L'appel au masculin prétendu neutre ou à des mots à genre non marqué, même quand les exemples, en revanche, n'évoquent que des femmes, est indicatif de cette tendance générale à ne pas restreindre le mot aux femmes. La question de fond a trait au sens construit par les pratiques discursives, et on va la poursuivre dans l'opposition sémantique entre feminista et machista (féministe et machiste). Le mot feminista porte une interrogation à propos de la distinction sociale entre féminin et masculin : uma (mulher) feminista « une (femme) féministe » / ?um (homem) feminista « ?un (homme) féministe ». Pour machista ( "machiste »), la désignation uma (mulher) machista « une (femme) machiste» est facilement acceptée dans les usages sociaux. Cette disparité a des effets sur la description lexicographique.

11 Revenons à l'Houaiss. Contrairement à ce qu'il fait pour feminista, pour décrire machista il ne donne pas d'exemple. L'effet de neutralité morphologique y est absolu, puisqu'il se sert du masculin prétendu neutre dans les deux définitions : « adjetivo e substantivo de dois gêneros $(s X X)$ - que ou aquele que pauta sua conduta pelo machismo (adjectif et substantif à deux genres - celui qui guide sa conduite par le machisme) » et «adjetivo de dois gêneros - relativo a machismo (adjectif à deux genres - relatif à machisme) $»^{4}$. Rappelons que pour feminista l'adjectif qui renvoie à un objet non-animé (une action) vient en premier, suivi par le fonctionnement adjectif-substantif attribué aux sujets. Pour machista, le substantif qui renvoie au sujet vient en premier. Le dictionnaire semble nous dire que tandis que le sujet machista et tout ce qui est relatif à lui est un donné évident, l'action féministe - la « contestation » - doit être reconnue socialement 
pour qu'un sujet prédiqué comme feminista puisse être reconnu. Cette interprétation s'impose avec une force accrue quand on examine les entrées machismo et feminismo.

Machismo, marqué comme substantif masculin du $\mathrm{XX}^{\mathrm{e}}$ siècle, reçoit les trois définitions suivantes : « 1 qualidade, ação ou modos de macho ('ser humano', 'valentão'); macheza (qualité, action ou manières de macho ['être humain', 'fanfaron']; qualité de macho) 2 infrm. exagerado senso de orgulho masculino ; virilidade agressiva ; macheza (infrml. Sens exagéré de fierté masculine; virilité agressive; qualité de macho) 3 comportamento que tende a negar à mulher a extensão de prerrogativas ou direitos do homem 'o m. ainda tem limitado o acesso feminino ao mercado de trabalho'(comportement qui tend à nier à la femme l'extension des prérogatives ou des droits de l'homme "le m. a encore limité l'accès féminin au marché de travail") »5. Dans les trois définitions, les hyperonymes qualité, action, manières, sens, virilité, comportement expliquent machismo comme une manière d'être.

13 A son tour, feminismo, marqué comme substantif masculin daté de 1905, reçoit les quatre définitions suivantes: « 1 doutrina que preconiza o aprimoramento e a ampliação do papel e dos direitos das mulheres na sociedade p. oppos. à antifeminismo " era uma defensora do f." > (doctrine qui prône l'amélioration et l'expansion du rôle et des droits des femmes dans la société p. oppos. à antiféminisme "elle était une partisane du f.") 2 p. met. movimento que milita neste sentido (p.mét. mouvement qui milite dans cette direction) 3 p. ext. teoria que sustenta a igualdade política, social e econômica de ambos os sexos (p. ext. théorie qui soutient l'égalité politique, sociale et économique des deux sexes) 4 p. mét. atividade organizada em favor dos direitos e interesses das mulheres ( $\mathrm{p}$. met. activité organisée pour les droits et les intérêts des femmes) $»^{6}$. Le premier hyperonyme du mot feminismo est doctrine, et les autres - mouvement, théorie, activité sont marqués comme extensifs ( $p$. ext.) ou métonymiques (p. met.) par rapport à lui. Le feminismo n'est pas expliqué comme une manière d'être, tel que le machismo. Il est expliqué comme corps d'idées, élaboration, action.

14 Alors que machismo est énoncé presque comme une donnée naturelle, intrinsèque de l'être, en faveur de l'homme et/ou contre les femmes, feminismo est énoncé comme action-élaboration pour l'égalité entre hommes et femmes ou pour les femmes. Entre ces deux mots qui peuvent paraître symétriques à première vue, il y a une histoire énonciative et discursive que le dictionnaire laisse entrevoir dans son mode de signifier, en interprétant les usages sociaux des mots. La construction des acceptions, les choix lexicaux, les rapports des définitions aux exemples ou même la présence ou l'absence d'exemples, tout concourt à organiser une représentation sociale des mots qui nous amène à considérer les effets discursifs rendus possibles par le fonctionnement de la langue. Le discours dominant - le machisme - est tellement fort que le dictionnaire efface la construction socio-historique du sens du mot, le signifiant comme une manière d'être. Et le discours dominé - le féminisme - apparait clairement comme une construction sociale, même s'il n'est pas énoncé explicitement comme une réponse au machisme.

15 Pour nous, les différences dans le fonctionnement de ces mots liés par la forme et le sens - feminista, machista, feminismo, machismo - doivent être renvoyées au rapport entre langue et interdiscours, ce qu'on examinera ensuite sur les réseaux sociaux. On pourrait donc reformuler notre question de départ en prenant en compte l'idée d'identification discursive. Au lieu de demander : « un homme peut-il énoncer au nom du féminisme? ", nous nous demanderons si quelqu'un qui se reconnaît ou est reconnu 
comme appartenant au genre masculin peut se contre-identifier aux discours qui constituent l'histoire de son genre et du genre qui lui est soumis dans ce processus historique.

\section{Hommes (qui se disent) féministes}

Depuis ces dernières années, on constate au Brésil une présence toujours croissante d'hommes dans les manifestations féministes urbaines: on les trouve dans la rue, aux côtés des filles, ils marchent aussi avec des inscriptions sur le dos et la poitrine, en portant des pancartes écrites à la main et énoncées en première personne, en reproduisant des cris de guerre des militantes féministes. Cette présence est largement diffusée par les médias et notamment via la circulation des photos et des publications (posts) dans les réseaux sociaux. La controverse est centrée sur la légitimité politique de la militance féministe par des hommes. Qui peut se dire/s'appeler féministe? Pour nous, il s'agit aussi et surtout d'une question de langage, dans cette énonciation, la désignation est mise en œuvre pour produire des identifications militantes. C'est dans le fil du discours, par la formulation des énoncés, qu'on peut explorer les traces de ces processus d'identification.

Nous considérons, en accord avec Eni Orlandi (2001) que l'identité est un mouvement du sujet du discours dans l'histoire, mouvement dont l'analyste peut tracer les trajets errants dans la matérialité du corpus étudié. Du point de vue discursif, l'identité, dans son unité imaginaire, est constitué par des processus d'identification de l'individu à des positions discursives à l'intérieur de l'interdiscours, processus qui sont de nature historique et idéologique et trouvent dans la langue leur lieu de réalisation. Ainsi, l'identité se présente à l'analyste du discours comme un faisceau instable de processus d'identification, dont la description mène à explorer aussi bien les images discursives et la scène énonciative, que les désignations développées au fil du discours. Dans ce senslà, nous admettons, en suivant Zoppi Fontana (2009), que les processus de désignation travaillent dans le discours comme des dispositifs de subjectivation/identification, non seulement à travers des noms propres, mais encore, et fondamentalement, à travers toutes les constructions (morpho)syntaxiques qui se réfèrent au / prédiquent le sujet du discours. En effet, c'est sur la base matérielle des désignations au fil du discours que des images discursives sont construites ${ }^{7}$, affectant les opérations énonciatives d'autoréférence qui représentent pour le sujet du discours son identité imaginaire : «je suis un homme féministe ».

Pour analyser ces processus d'identification sur la base des formes de la langue et d'autres formes matérielles, nous prenons ici comme corpus des discours numériques natifs (Paveau 2015). Dans l'actualité, les différentes formes de cyber-militance jouent un rôle majeur dans les mouvements féministes, avec une présence massive dans les réseaux sociaux. Au Brésil, ces féminismes de quatrième génération ${ }^{8}$ occupent un espace polémique et favorisent l'émergence de plusieurs collectifs, dont l'action politique se multiplie par l'effet de la dispersion spatiale et de la temporalité instantanée du numérique. Leurs arguments et leurs pratiques rhétoriques-esthétiques ouvrent de nouvelles approches à la problématique féministe, dans son hétérogénéité croissante, et sont réappropriés par l'espace académique et politique institutionnels. Nous explorons les communautés intitulées « Hommes féministes ", « Homme féministe pour de vrai », «Homme féministe », «Homme pro-féministe » qui ont été récemment 
crées sur le web 2.0 (Facebook, Twitter). Ces désignations se multiplient sur le réseau et produisent des effets polémiques sur les blogs féministes plus actifs dans la cybermilitance brésilienne actuelle.



Figure 1 : Hommes féministes (communauté)

Source : http://www.facebook.com/homensfeminismo.

$1^{\circ}$ post 3/4/2014 - dernier post 31/10/2016 en activité, 1.329 likes à 2/11/2016

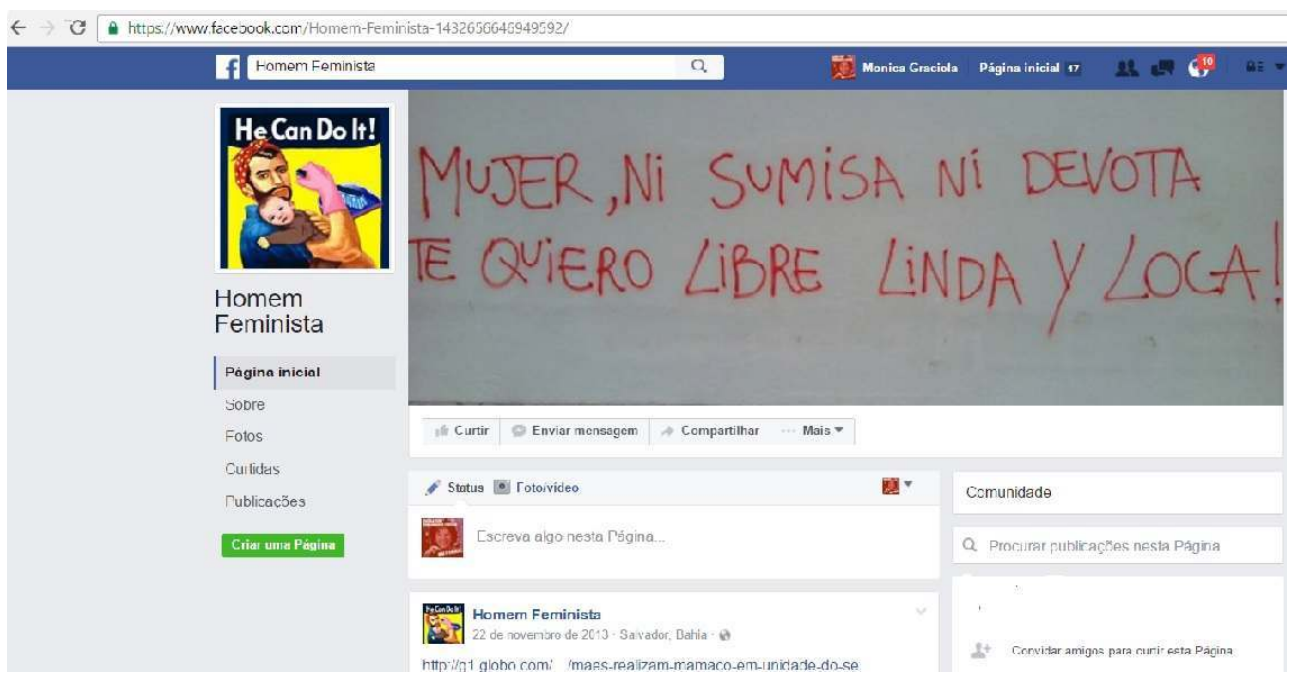

Figure 2 : Homme féministe (communauté)

Source : http://www.facebook.com/Homem-Feminista-1432656646949592/

$1^{\circ}$ post 21/11/2013 - dernier post 22/11/2013, 163 likes à 2/11/2016 


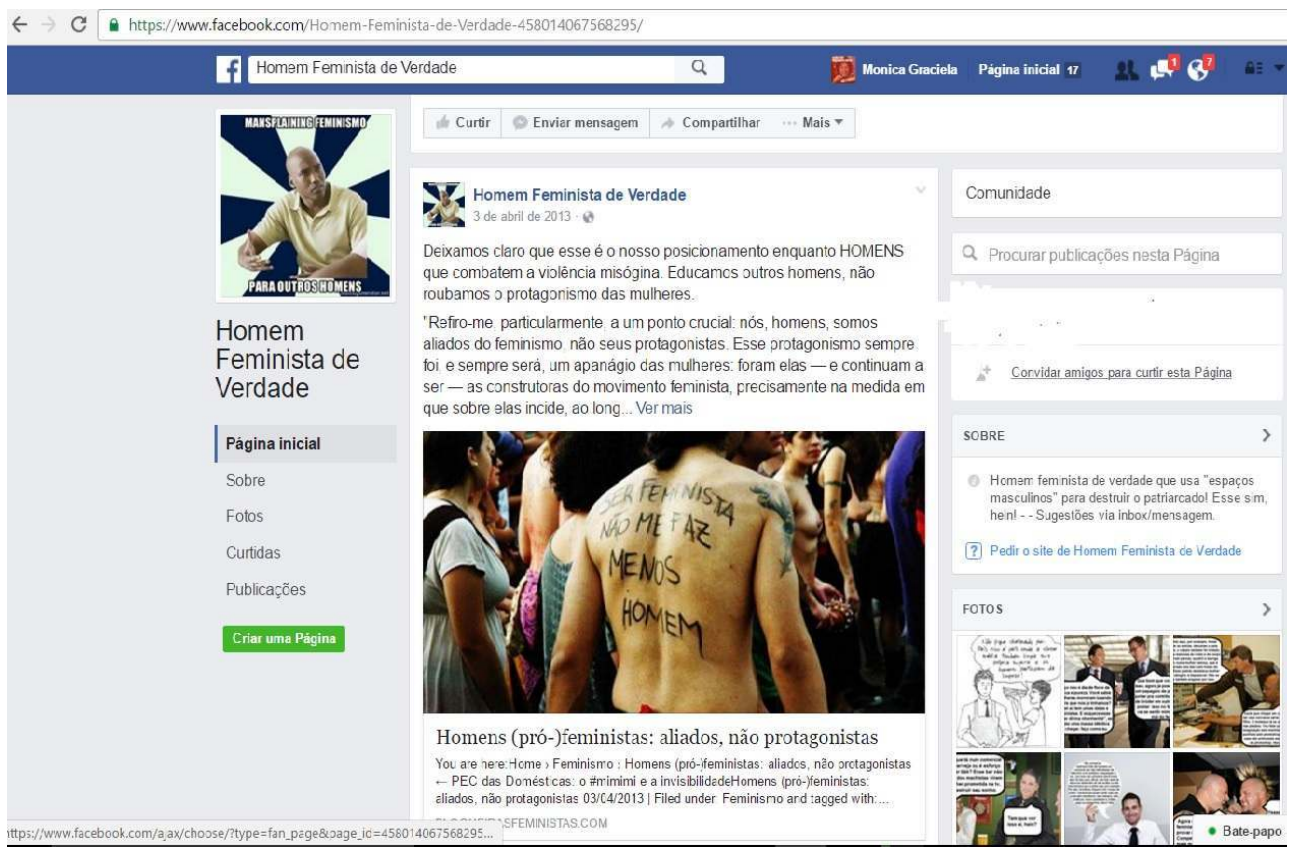

Figure 3 : Homme féministe pour de vrai (communauté)

Source : https://www.facebook.com/Homem-Feminista-de-Verdade-458014067568295/

$1^{\circ}$ post 12/12/2012 - dernier post 3/4/2013, 10.448 likes à 2/11/2016

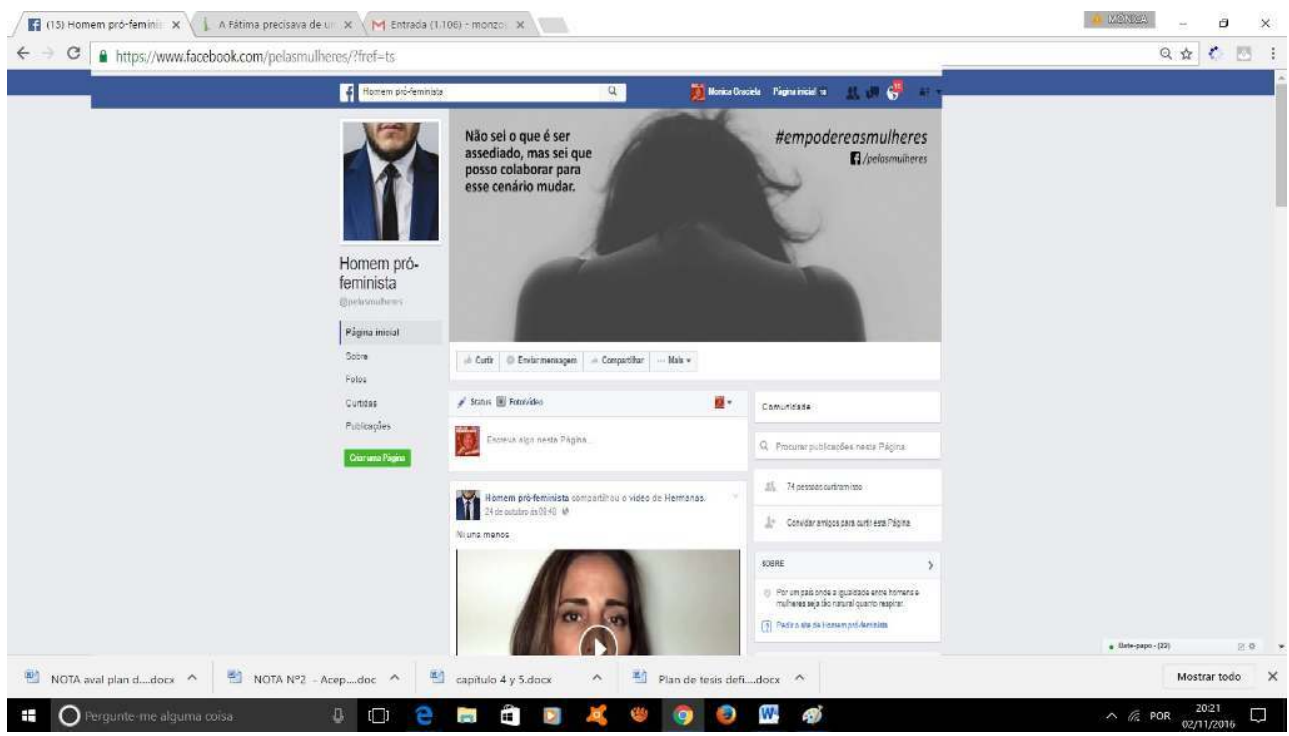

Figure 4 : Homme pro-féministe (communauté)

Source : https://www.facebook.com/pelasmulheres/

$1^{\circ}$ post 2/3/2016 - dernier post 24/10/2016 en activité, 74 likes à 2/11/2016

Parmi les quatre communautés citées, seulement deux - Figure 1 : Hommes féministes et Figure 4: Homme pro-féministe-sont encore en activité; pour les deux autres, la dernière publication est datée de 2013. La différence entre elles est aussi marquée par leur popularité sur le réseau, dont le nombre de likes est un indicateur La communauté la plus populaire - Homme féministe pour de vrai- est aussi la seule qui ait investi dans la production de mèmes didactiques, dont il est possible de voir un petit échantillon à 
droite sur la Figure 3 ; toutes les autres se limitent à commenter et répliquer, plutôt que créer, des textes publiés ailleurs sur des blogs féministes. Il y a encore parmi les publications quelques articles originaux qui réfléchissent sur les événements ou les nouvelles d'actualité.

Nous analyserons d'abord les noms des communautés, puis les positions énonciatives de leurs locuteur.trice.s et les représentations visuelles construites par les images de profil et de couverture. Enfin nous passerons à l'observation des posts et des blogs à finalité didactique.

\subsection{Les noms des communautés}

21 Les noms des communautés sont construits à partir de la détermination du nom homme(s) par l'adjectif féministe(s), auxquels il est ajouté un complément prépositionnel de verdade (pour de vrai) ou le préfixe pro-. La détermination est ainsi un indice de la division qui affecte le sens du mot homme dans l'énonciation et signale aussi l'instabilité des désignations résultant de cette opération. Le geste de dire homme féministe suppose l'existence d'autres désignations pour référer à l'ensemble constitué par les individus qui se reconnaissent comme étant du genre masculin. Ainsi la construction homme féministe ne parle pas d'un homme ou des hommes, mais d'un homme d'un type particulier par opposition à d'autres types spécifiés par différentes déterminations : " hommes machistes", "vrais hommes", " hommes possibles", etc. On trouve sur le réseau des communautés, des pages et des profils qui sont nommés de cette façon, ce qui montre les rapports polémiques institués entre ces désignations dans leur circulation dans le discours numérique. En outre, les déterminations de cette construction (" homme féministe pour de vrai », « homme pro-féministe »), qu'on voit apparaître fréquemment sur le réseau, peuvent être interprétées comme un symptôme de l'instabilité de ce processus de désignation: on pourrait toujours ajouter une nouvelle détermination qui signalera/produira une nouvelle ligne de fracture, une nouvelle division du sens. De cette façon, l'opération sémantique de détermination est l'indice au fil du discours d'une interprétation de non-coïncidence entre les mots et les choses et entre discours différents (Authier-Revuz 1995), qui est projetée par le sujet au cours de son énonciation. Cette non-coïncidence référentielle et discursive résulte du débat idéologique mené dans la société pour stabiliser le sens de la désignation homme dans la langue. La détermination en "homme féministe pour de vrai» indique par inférence une opposition avec des désignations du type « homme pseudo-féministe » et "homme faussement féministe », lesquelles circulent de manière polémique sur les réseaux sociaux. De la même façon, la détermination par le préfixe pro- suppose l'opposition à d'autres préfixes comme anti - ou contra -, et donc il peut être interprété aussi comme une marque du rapport conflictuel au discours machiste ${ }^{9}$. Mais cette marque ne se réduit pas à signaler une opposition polarisée, antagonique, puisqu'elle produit une double détermination : elle constitue un travail sur les frontières mobiles et poreuses entre les positions discursives féministes et machistes, mais aussi et notamment à l'intérieur des positions féministes. En effet, le préfixe pro- met en scène une division dans le champ des féminismes qui distingue des militant.e.s de façon non symétrique et hiérarchisée. Il s'agit d'une distinction par rapport au lien d'appartenance au collectif et au droit d'énonciation légitime, selon qu'ils/elles s'identifient et qu'ils/elles sont reconnu(e)s comme étant du genre masculin ou féminin. L'adjectif féministe ne pourrait être attribué qu'aux désignations qui se 
réfèrent aux femmes; en revanche, le préfixe pro- ne peut être ajouté à l'adjectif féministe que dans le cas d'une désignation dont le nom déterminé se réfère au genre masculin : « homme(s) proféministe(s) », « militant(s) proféministe(s) ».

Ainsi, par le seul effet de leurs noms propres, ces communautés Facebook révèlent l'existence d'un conflit de légitimation de nouveaux sujets politiques pour les mouvements féministes.

\subsection{Qui parle dans les communautés d'hommes féministes ?}

Une autre trace qui mérite une explication est l'utilisation du pluriel ou du singulier dans la construction de la désignation : homme ou hommes? Ce petit détail grammatical a cependant des effets majeurs sur la représentation de la scène énonciative et donc sur la construction de l'image du locuteur, tel qu'il est représenté dans les énoncés. Les figures 2, 3 et 4 représentent l'utilisation au singulier de la dénomination: «Homme pour de vrai / pro- / féministe »: la figure 1 représente son utilisation au pluriel: «Hommes féministes». Dans le premier cas, la dénomination au singulier permet l'ancrage imaginaire de l'énonciation dans l'espace subjectif du moi : c'est un je qui parle. Cet effet énonciatif peut être renforcé par la présence d'énoncés en première personne du singulier, comme dans la figure 4 , où on trouve sur l'image de la couverture de la page l'énoncé suivant : «Je ne sais pas ce que c'est de se faire harceler, mais je sais que je peux contribuer à changer cette scène " [Não sei o que é ser assediado, mas sei que posso colaborar para esse cenário mudar].

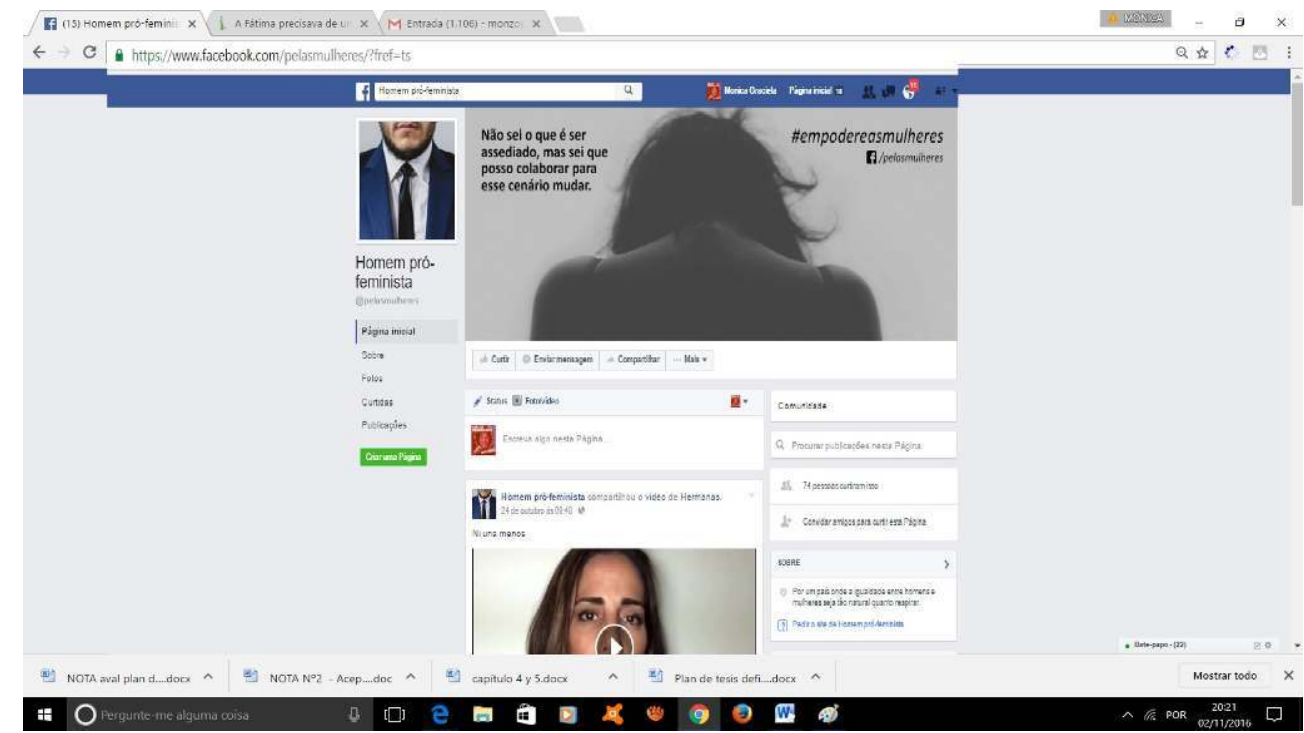

Figure 4 : Je ne sais pas ce que c'est de se faire harceler, mais je sais que je peux contribuer à changer cette scène

Source : https://www.facebook.com/pelasmulheres/photos/a.

1103603612994972.1073741828.1045627458792588/1103603379661662/?type=1\&theater

Toutefois, le rapport entre la forme au singulier - homme féministe - et la représentation du locuteur comme un « je qui parle » n'est ni simple ni univoque. Dans la communauté "Homme féministe pour de vrai », on repère des énoncésqui se réfèrent aux hommes du collectif comme groupe d'individus distincts qui, sur la page, assument tous la fonction d'auteur. De cette façon, un locuteur collectif qui ne se dit pas «nous » ni se 
représente comme un «je qui parle» est mis en scène; mais il s'inclut dans la prédication homme féministe pour de vrai. Nous prenons comme exemple le post publié le 8 décembre, 2013 :

Les hommes de la page Homme féministe pour de vrai sont complètement choqués par la publicité de Gilette, mais le pire c'est que ce même type de charge existe contre les femmes depuis des décennies (s'il vous plaît, faites attention au mot « décennies ", il n'y a rien d'essentiel ou de naturel pour l'humanité).

[Os homens da página Homem Feminista de Verdade ficam, sim, muito passados com a propaganda da Gilette, mas o pior mesmo é que esse mesmo tipo de imposição é feito há décadas contra mulheres (por favor, observe o "décadas", isso não é algo essencial e natural da humanidade)].

D'autre part, dans la communauté intitulée « Hommes féministes » (Figure 1) on trouve parmi les publications les plus anciennes, des posts signés par des femmes. Cette marque d'identification de l'auteur.e dans le corps du texte du post est assez surprenante et inattendue par rapport au fonctionnement des publications sur des pages Facebook, dans lesquelles il existe déjà une attribution d'auteur.e par l'image de profil et le nom de la communauté. Ce marquage peut être interprété comme un indice de la gêne ressentie par les sujets qui sont réuni.e.s dans le collectif par rapport à l'hétérogénéité constitutive de cette communauté et à la légitimation différentielle de leurs lieux d'énonciation. Ainsi, nous trouvons de 26 mai à 18 juin de 2015 une dizaine de posts signés par : « Adm : [XWZ nom féminin] » ou « Adm : [YWZ nom masculin]».



it Curtir an Comentar A Compartilhar Be

Figure 5a

Source : https://www.facebook.com/homensfeminismo/posts/ 
Homens Feministas

11 de junho de 2015 - e

Vocês concordam quando afirmamos que homens podem ser feministas?

$\sim$ Adm: Welliton

\section{Curtir $\quad$ Comentar Compartilhar}

Figure $5 b$

Source : https://www.facebook.com/homensfeminismo/posts/

Cette pratique d'auteur s'est arrêtée après les premiers posts, mais pour nous elle témoigne de l'hétérogénéité des locuteurs qui sont réunis indistinctement sous l'étiquette d'homme féministe. Il est également surprenant de trouver des posts où on voit apparaître la représentation d'une locutrice prenant la parole, ce qui peut être observé dans la Figure 6 (en bas).

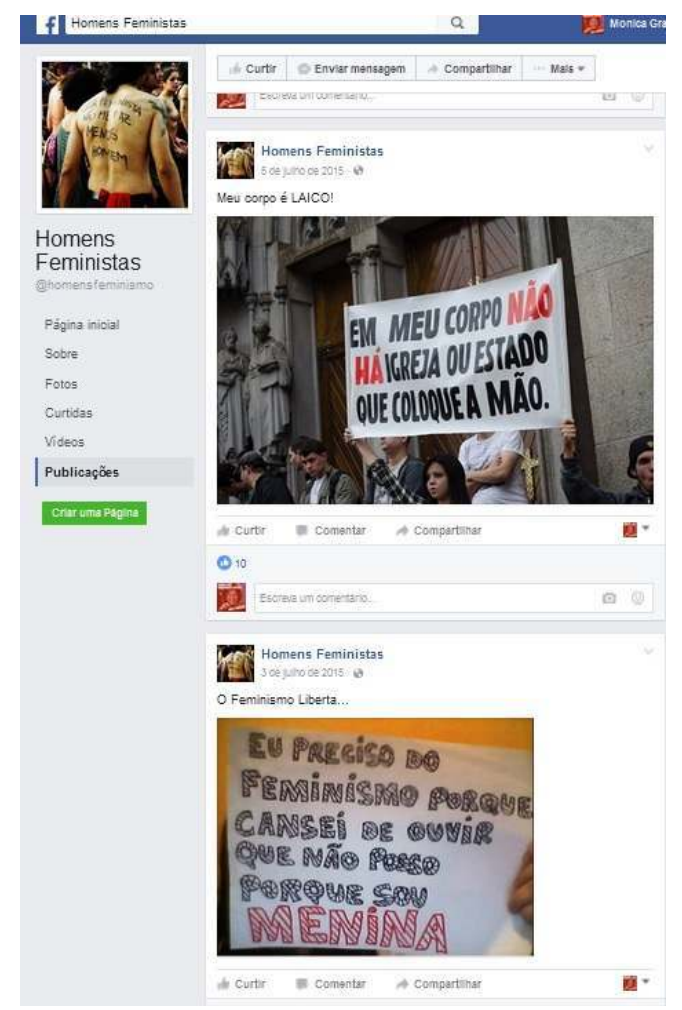

\section{Figure 6}

Source : https://www.facebook.com/homensfeminismo/posts/

Hommes féministes

5 juin, 2015

Mon corps est laïc.

[Dans la photo] Sur mon corps ni l'Église ni l'État posent leurs mains.

Le féminisme libère.

[Dans la photo] J'ai besoin du féminisme parce que ça suffit d'entendre que je ne peux pas parce que je suis une fille. 
Dans la même communauté, on trouve encore des énoncés où le locuteur se représente comme un «nous hommes et femmes féministes».

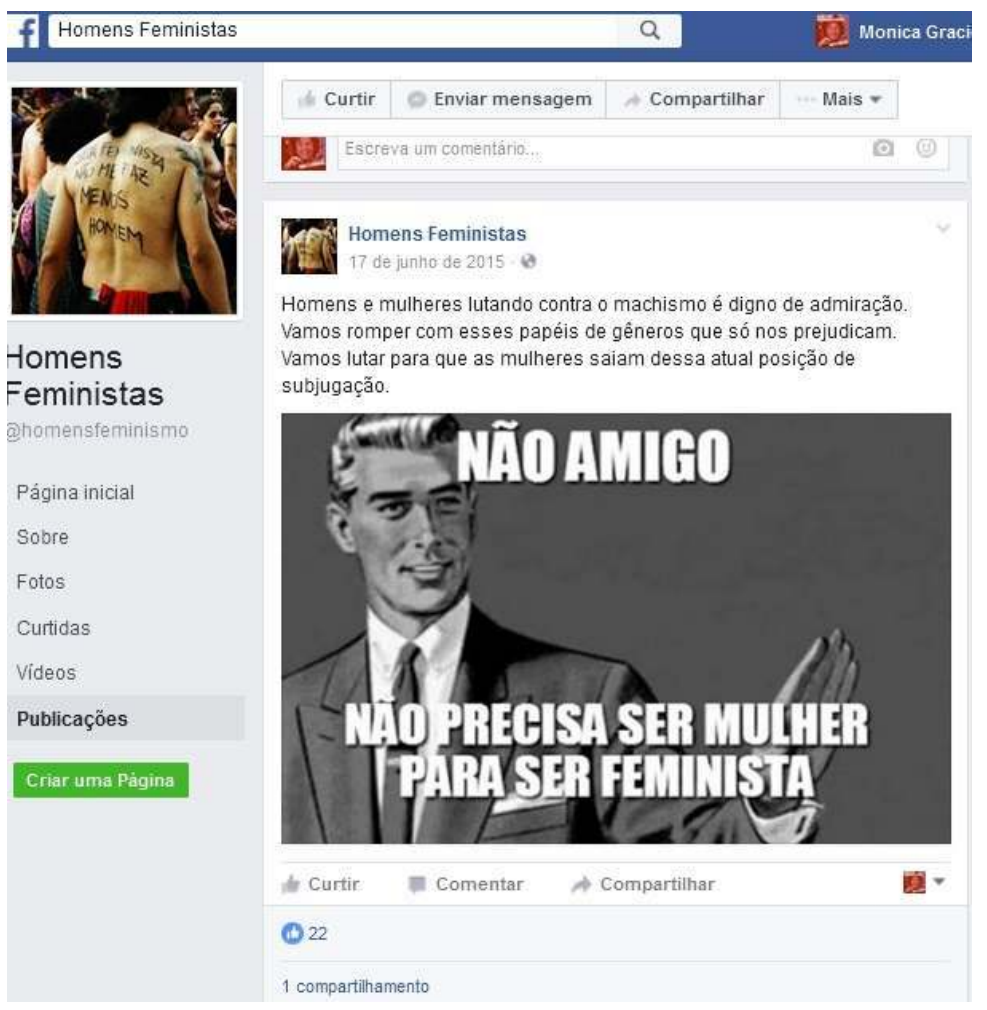

Figure 7

Source : https://www.facebook.com/homensfeminismo/photos/a.

1615776855301052.1073741829.1478359699042769/1625725737639497/?

type=3\&theaterHommes féministes

17 juin, 2015

C'est digne d'admiration : hommes et femmes en lutte contre le machisme. Allez! on va briser ces rôles de genre qui ne font que nous nuire. On va lutter pour que les femmes sortent de leur position actuelle de soumission.

NON, MON AMI, IL NE FAUT PAS ÊTRE FEMME POUR ÊTRE FÉMINISTE

Cette division hétérogène du nous représenté à la place du locuteur des communautés dites d'hommes féministes pose la question suivante: qui parle/énonce dans les communautés Facebook auto-désignées comme de(s) homme(s) / pour de vrai /pro-/ féministe(s)?

\subsection{Matérialités visuelles : images de profil et de couverture}

Pour répondre à cette interrogation, il faut prendre en compte, comme nous l'avons déjà fait plus haut, la matérialité visuelle des textes en analyse et surtout insister sur la matérialité discursive de la scène énonciative : nous analysons les images discursives (c'est-à-dire des représentations) construites et circulant dans le discours numérique et non les sujets empiriques qui écrivent les textes sur les réseaux. L'image du profil et l'image de la couverture de la page, étant deux espaces textuels propres aux réseaux sociaux, ils peuvent servir d'observatoire pour la construction des images discursives qui opèrent comme une mise-en-corps du locuteur des énoncés. 
es quatre communautés représentent la figure d'un homme (en photo ou en dessin), dans leurs images de profil. Trois de ces images font aussi des citations explicites aux discours des mouvements féministes, soit par l'incorporation de leurs termes soit par l'inclusion de leurs images iconiques. Ainsi, dans la Figure 3 (communauté « Homme féministe pour de vrai») on lit l'énoncé "Mansplaining du féminisme pour d'autres hommes » superposé à l'image de profil : il s'agit en même temps de l'appropriation du vocabulaire féministe (mansplaining ${ }^{10}$ ) et de l'inversion du destinataire de l'énoncé ppar la réinterprétation de la désignation qui est re-signifiée comme «des hommes qui expliquent ce qui est évident à d'autres hommes ». De la même façon, dans la Figure 5 (communauté « Hommes féministes »), l'image du profil reprend une photo qui montre le dos nu d'un homme qui porte sur la peau l'inscription : "être féministe ne me fait pas moins homme" [ser feminista não me faz menos homem]. Cette photo ${ }^{11}$ a une circulation virale sur les réseaux sociaux brésiliens et elle sert d'illustration à un article à propos de la place des hommes dans les mouvements féministes publié dans «Blogueuses féministes »[Blogueiras feministas], mais signé par un homme, qui est largement cité ou repris par tout texte militant qui s'interroge sur cette question ${ }^{12}$.

BLOGUEIRAS

FEMINISTAS

\section{Homens (pró-)feministas: aliados, não protagonistas}

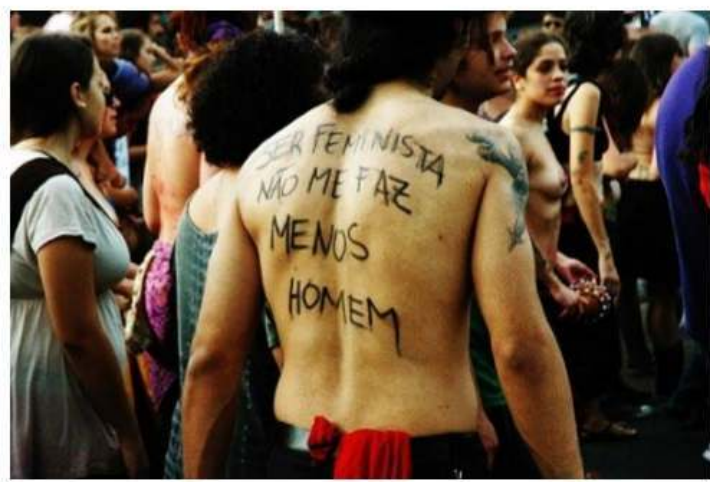

If $\mathbf{t}$ or

Texto de Henrique Marques-Samyn.

Figure 3 : (détail, v. plus haut)

Source : http://blogueirasfeministas.com/2013/04/homens-pro-feministas-aliados-naoprotagonistas/

D'autre part, dans la figure 2 («Homme féministe ») l'image du profil présente une version modifiée d'une affiche iconique du mouvement féministe des année 1980. L'image fait allusion explicitement à l'affiche originale, mais remplace la figure de la femme par la figure d'un homme qui s'occupe des enfants et des affaires domestiques. L'énoncé HE CAN DO IT, qui accompagne l'image, est une relecture de l'énoncé de l'affiche originale WE CAN DO IT, qui était superposé initialement à l'image d'une ouvrière $^{13}$. De cette façon, l'image de profil d'une communauté auto-appelée «homme 
féministe" semble représenter la scène énonciative comme une énonciation des femmes destinée à d'autres femmes, ayant pour objet les hommes. Un autre indice qui renforce cette interprétation est la présence des thèmes plus dirigés vers le public féminin, comme l'allaitement ou le débat entre différents féminismes ayant des femmes comme sujets politiques. S'agirait-il d'une page/communauté fake? Serait-ce peut-être cela l'explication de la durée trop courte de l'activité de cette page (un seul jour!)? Nous ne pouvons que signaler l'équivoque et en analyser les effets de sens.

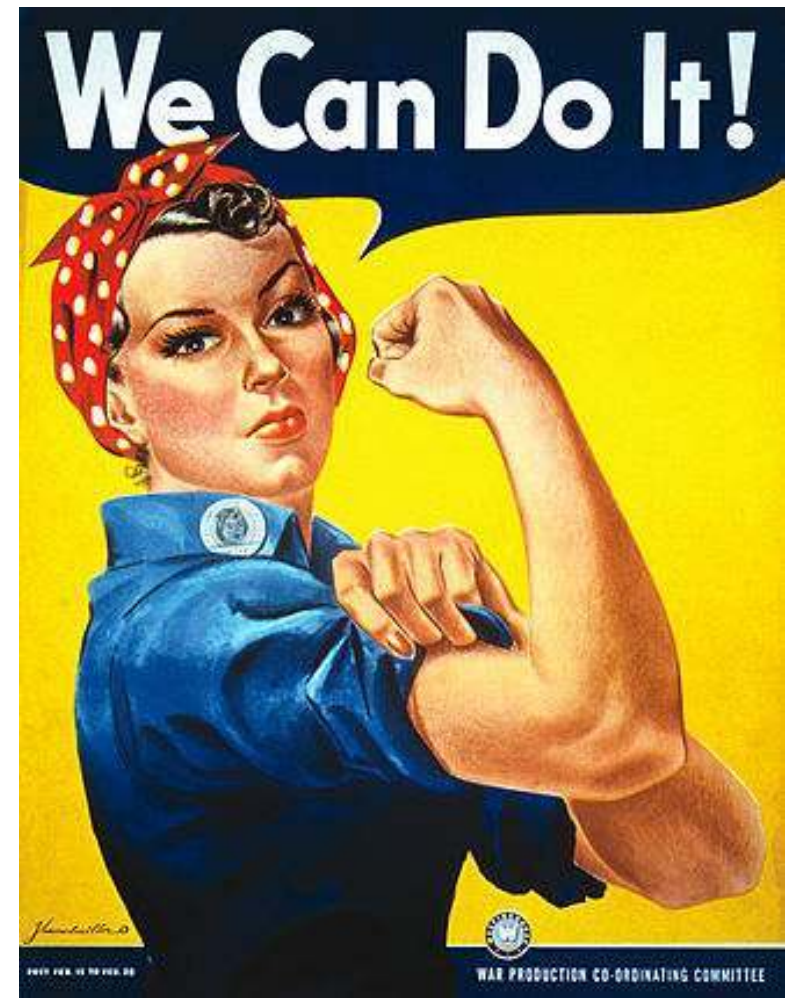

Figure 8a : We Can Do It!

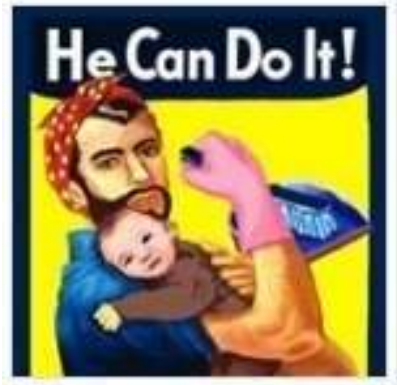

Figure 8b : He Can Do It!

Cette équivocité de l'image du profil s'ajoute aux effets détournants de l'image de la couverture de la page, qui représente une inscription sur le mur (écrite en espagnol), dans laquelle on lit «Femme, ni soumise ni dévote, (je) te veux libre, jolie et folle ». Le locuteur de ces énoncés est représenté comme un je qui parle, mais l'identification au lieu social ${ }^{14} \mathrm{~d}^{\prime} u n$ homme n'apparaît pas clairement ni de façon immédiate. 




Figure 9

Source : https://www.facebook.com/1432656646949592/photos/a

$1432668440281746.1073741827 .1432656646949592 / 1432668373615086 /$ ?type=1\&theater

A qui est due l'inscription sur le mur? Un homme parle-t-il pour une femme? Une femme pour une autre femme? Le je qui parle reste indéfini et opaque par rapport au genre et ne peut être interprété que par rapport au nom de la communauté - «Homme féministe » - et à l'image du profil (laquelle renforce l'équivoque, comme on l'a montré en haut). Le seul commentaire - «Tiens, qu'est-ce qu'il y en a des femmes masculistes » [E como tem mulher masculista] -ajouté par une internaute (dont le nom et l'image du profil féminin sont ici préservés) révèle l'équivoque énonciative de l'inscription qui sert de couverture. Dans son commentaire, l'internaute dénonce le masculinisme ${ }^{15} \mathrm{de}$ la phrase, donc le point de vue masculin qui supporte l'énonciation, en même temps qu'elle ne l'approche pas dans une perspective féministe. Ainsi, par un effet de modalisation emphatique de l'énoncé, la désignation femme masculiste ne s'aligne pas idéologiquement à la désignation homme féministe qui dénomme la communauté, mais fait allusion à une autre, qui reste implicite : homme masculiste.

Les analyses développées jusqu'ici sur le processus de désignation et la représentation de la scène énonciative sur la page des communautés Facebook nous permettent de conclure que la désignation Homme féministe (et ces variantes : « homme féministe pour de vrai », «homme pro-féministe ») est une étiquette qui renvoie à des images contradictoires, polysémiques. Ces images rendent opaque et équivoque le processus d'identification du genre des locuteurs et /ou des destinataires. Après avoir examiné les formes des noms, les positions énonciatives et les matérialités visuelles des hommes se réclamant du féminisme, observons ce qu'il en est dans les discours tenus.

\section{3. Être un homme (pro-)féministe : pratiques de soi et discours instructionnel}

De quoi parlent les hommes féministes sur les réseaux sociaux? Quels sont les thèmes abordés dans les posts publiés sur les communautés Facebook? Une exploration des quatre communautés qui nous occupent révèle que la plupart des publications sont des repostages de textes publiés ailleurs, notamment sur des blogs féministes. Cette republication est parfois accompagnée d'une introduction nouvelle, qui souligne 
quelques propositions du texte ou qui explicite une prise de position par l'auteur.e du repostage. C'est ainsi que nous trouvons sur les pages de toutes les communautés analysées la republication de l'article «Hommes (pro-)féministes: alliés, non protagonistes" [Homens (pró-)feministas: aliados, não protagonistas], publié à l'origine dans «Blogueuses féministes». À titre d'illustration nous prenons le post sur la communauté « Homme féministe pour de vrai » :

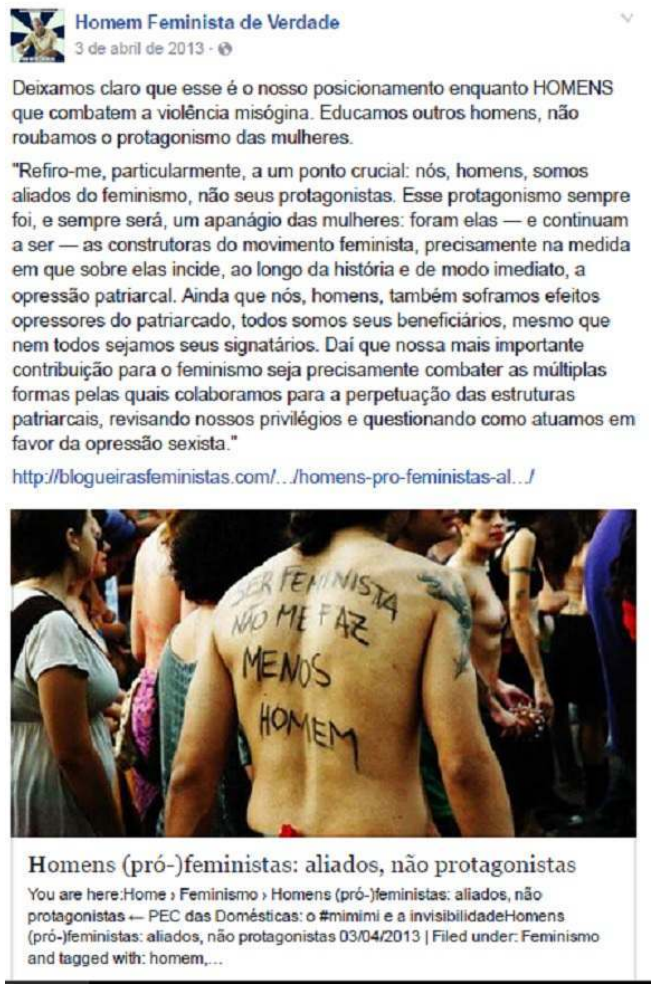

Figure 10

https://www.facebook.com/Homem-Feminista-de-Verdade-458014067568295/

Homme féministe pour de vrai 3 de abril de 2013

Nous affirmons clairement que telle est notre position en tant qu'HOMMES qui combattent la violence misogyne. Nous éduquons d'autres hommes, nous ne volons pas le protagonisme des femmes.

«Je me réfère en particulier à un point crucial : nous sommes des hommes alliés du féminisme, et pas ses protagonistes. Ce rôle a toujours été, et sera toujours un apanage des femmes : elles ont été - et demeurent - celles qui ont construit le mouvement féministe, précisément dans la mesure où c'est sur elles que s'exerce, à travers l'histoire et de façon directe, l'oppression patriarcale. Bien que nous, les hommes, souffrions aussi des effets oppressifs du patriarcat, nous en sommes tous les bénéficiaires, même si tous n'en sont pas les signataires. Donc notre contribution la plus importante au féminisme est précisément de lutter contre les multiples façons dont nous contribuons à la perpétuation des structures patriarcales, en examinant nos privilèges et en remettant en question la façon dont nous agissons en faveur de l'oppression sexiste. »

Cette dynamique de republication commentée, majoritaire dans les communautés autodéfinies comme collectifs d'hommes féministes, peut être analysée comme une énonciation au second degré. Il s'agit de l'inclusion d'une réflexion importée, sous forme de citation textuelle et d'autres formes de discours rapporté, favorisées par la simplicité et l'instantanéité de la fonction de partage des réseaux sociaux. Nous 
appelons « énonciation cautionnée » ce dispositif énonciatif, car sa légitimation et son autorisation argumentative est donnée par un locuteur qui est ailleurs: ce sont des femmes qui définissent et disent ce qu'est être un homme féministe. Même si le texte est signé par un homme, cette caution énonciative est encore présente, soit en raison de sa publication première sur un blog des femmes, soit pour une mention explicite à l'évaluation ou collaboration des femmes dans sa rédaction. Le premier cas est illustré par l'article "Hommes (pro-)féministes: alliés, non protagonistes ", que nous avons déjà mentionné, dont l'auteur se reconnaît explicitement comme un homme par sa signature et sa biographie « Auteur : H. M.-S. Homme, noir, proféministe. Écrivain et professeur à l'UERJ » [Autor: H. M.-S. Homem, negro, pró-feminista. Escritor e professor da UERJ]. Néanmoins, le texte est publié à l'origine dans « Blogueuses Féministes », d'où il est repris à l'identique, avec la mention explicite de sa source première. Le second type d'énonciation cautionnée est illustrée par l'article « 10 choses que les hommes peuvent faire pour soutenir le féminisme », publié sur le site BuzzFeed en 17 mai de 2016 et signé aussi par un auteur qui s'identifie comme un homme par son nom et sa photo de profil. À la fin de l'article, l'auteur précise : «Ce post a été préparé avec l'aide des militantes féministes R.C. et C.P. ».

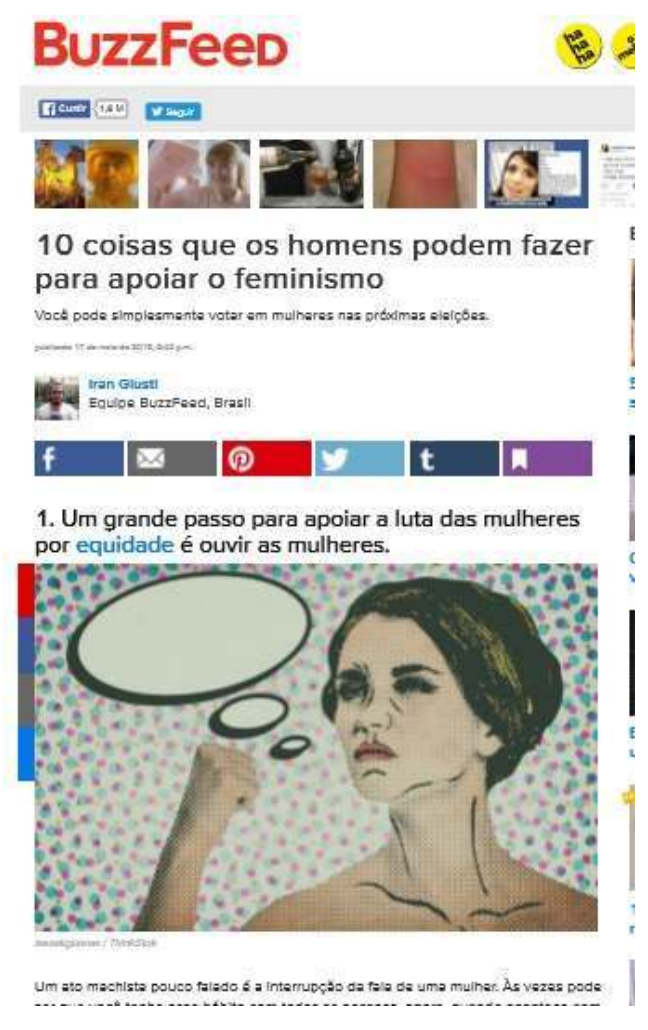

Figure 11

Source : https://www.buzzfeed.com/irangiusti/10coisasqueoshomenspodemfazerparaapoiarofeminismo?utm_term=.scOvQPpra\#.xtn6bGYyv

Nous trouvons une remarque semblable à la fin du dossier «Féminisme pour les hommes, un cours rapide » [Feminismo para homens, um curso rápido], publié sur le blog « bavardage entre hommes " [Papo de homem], également signé par un auteur qui se présente explicitement comme un homme :

Ce texte a été écrit et republié en janvier 2014 pour améliorer l'argumentation, exclure des extraits faibles et rendre le langage moins sexiste [...]. Je remercie 
toutes les femmes, maîtres, professeures, déesses du féminisme qui m'aident chaque jour dans la tâche infinie de dire moins de bêtises et d'être davantage proféministe. (https://papodehomem.com.br/feminismo/)

[Esse tex to foi reescrito e republicado em janeiro de 2014, para melhorar argumentação, excluir trechos fracos e tornar a linguagem menos sexista [...] Obrigado a todas as mulheres, mestras, professoras, deusas do feminismo,que todo dia me ajudam na incansável tarefa de falar menos besteira e ser mais prófeminista.]

Outre la reproduction de textes militants des blogs féministes, les communautés et les blogs d'hommes féministes assurent aussi une publication abondante de textes à finalité didactique qui enseignent aux hommes comment agir pour soutenir le féminisme et attaquer les discours et les pratiques machistes. Ces textes se présentent comme des mèmes didactiques ou des listes de commandements comportementaux. Les mèmes sont par exemple la stratégie préférée de la communauté «Homme féministe pour de vrai ».

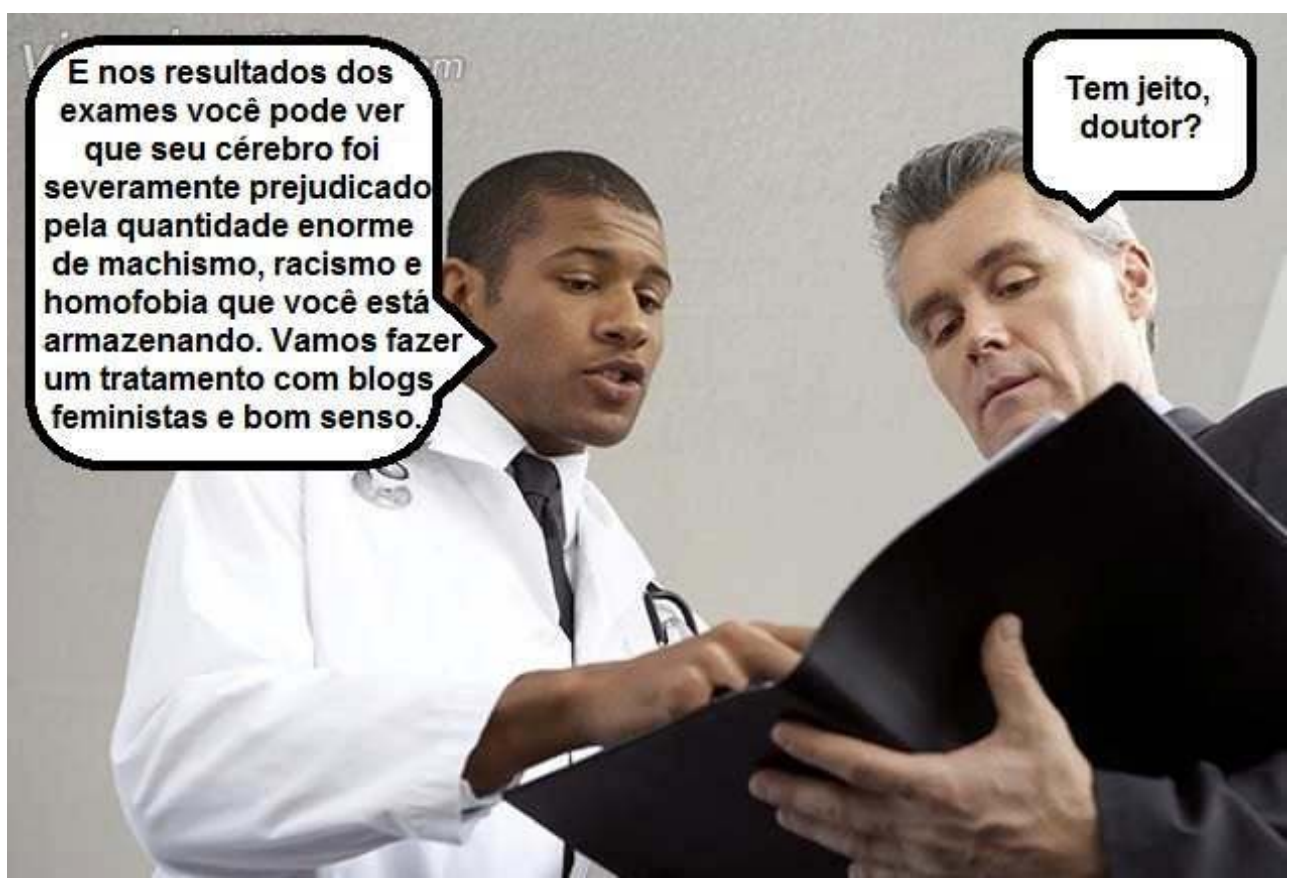

Figure 12

Source : https://www.facebook.com/Homem-Feminista-de-Verdade

- Et dans les résultats des examens vous pouvez voir que votre cerveau est gravement affecté par la quantité énorme de machisme, racisme et homophobie que vous stockez. Nous allons faire un traitement avec des blogs féministes et du bon sens.

- Ça peut marcher, docteur?

39 En ce qui concerne les listes de commandements, prenons, par exemple, le décalogue établi dans l'article de BuzzFeed déjà mentionné ( $« 10$ choses que les hommes peuvent faire pour soutenir le féminisme ») :

- Indiquez toujours les femmes pour les postes vacants et si vous travaillez avec plus d'hommes que de femmes, demandez à vos supérieurs pourquoi.

- Au moment d'embaucher des femmes, préférez les mères et les femmes célibataires.

- Faites le ménage, et si vous ne savez pas le faire, apprenez (https:// 
www.buzzfeed.com/irangiusti/10coisasqueoshomenspodemfazerparaapoiaro-

feminismo?utm_term=.scOvQPpra\#.xtn6bGYyv).

[-Sempre indique mulheres para vagas de emprego e, caso trabalhe com mais homens do que

mulheres, questione seus superiores o porquê.

- Na hora de contratação de mulheres, dê preferência para mães e mulheres solteiras.

- Faça trabalhos domésticos, e se você não sabe, aprenda].

Nous pouvons rapprocher ces commandements $d u$ fonctionnement du discours injonctif-instructionnel: ils donnent des conseils, des instructions pour agir à la manière des féministes et contre le machisme. De plus, ces textes produisent des jugements axiologiques qui distinguent des attitudes et des comportements corrects, bienveillants et justes concernant les relations de genre. Il s'agit de textes normatifsprescriptifs qui font un travail idéologique sur les frontières faibles entre les discours d'instruction, de recommandation et de prescription, comme le montre l'exemple suivant :

Donc, je le souligne : nous, les hommes pro-féministes, essayons nous- mêmes de nous consacrer à faire notre part; interrogeons-nous sur nos privilèges, développons nous-mêmes des stratégies pour permettre la délimitation de nos propres devoirs et responsabilités et pour agir comme des alliés des femmes féministes - elles, les véritables protagonistes de cette lutte. À mon avis, c'est la manière la plus légitime et la plus productrice d'agir en faveur de la construction d'un monde vraiment/effectivement libre de toute oppression sexiste. (http:// blogueirasfeministas.com/2013/04/homens-pro-feministas-aliados-naoprotagonistas/)

[Por isso, ressalto: que nós, homens pró-feministas, dediquemo-nos a fazer a parte que nos cabe; tratemos de questionar nossos privilégios, de desenvolver estratégias que permitam a delimitação de nossas próprias atribuições e responsabilidades e de atuar como aliados junto às mulheres feministas - elas, sim, protagonistas nessa luta. A meu ver, esse é o modo mais legítimo e produtivo de agirmos em favor da construção de um mundo efetivamente livre da opressão sexist.]

41 La dimension didactique est traversée, donc, par la dimension axiologique/éthique du discours (Paveau 2013); nous avons affaire à un discours à fort effet normatif. Les énoncés esquissent une image discursive qui donne un modèle idéal d'homme auquel tout militant féministe doit s'identifier. Cette identification demande des militants une pratique réflexive constante par laquelle le sujet s'examine et contrôle ses comportements et ses pensées. Les communautés et les blogs d'hommes féministes ou proféministes prônent de cette manière un ensemble de pratiques de soi qui sont supposées produire, si elles sont bien suivies, une transformation subjective. Foucault, dans «L'éthique du souci de soi comme pratique de la liberté » (texte qui reprend un entretien de 1984), affirme que le souci de soi est une pratique d'autoformation du sujet, un exercice de soi sur soi par lequel on essaie de s'élaborer, de se transformer et d'accéder à un certain mode d'être. Ces pratiques s'exercent au sein de différents dispositifs. Dans nos exemples, ces dispositifs sont les communautés et les blogs d'hommes féministes, qui dans leur matérialité numérique multiplient la circulation des textes et ainsi la capacité d'accès à des publics distincts. Le numérique, agissant comme un grand miroir, projette des images qui pourront favoriser des effets d'identification (ou contre-identification) féministe pour et par les hommes. Ces processus d'identification se matérialisent dans les énoncés comme une énonciation du moi ; on trouve la représentation d'un «je homme féministe qui parle», comme par exemple dans le «Manifeste Hommes libérez-vous!», publié sur la communauté « Hommes Féministes » le 29 juin de 2015 : 
- Je sais que le féminisme est une lutte pour l'égalité de tous les individus.

- Je vais me libérer, non pour opprimer les femmes, mais pour que nous puissions tous être libres ensemble.

- La société m'a appris à être macho et j'ai besoin d'aide pour me rendre compte si j'opprime quelqu'un avec mes attitudes.

[ -Eu sei que o feminismo é uma luta pela igualdade entre todos os indivíduos.

- Eu vou me libertar, não para oprimir mais as mulheres, mas para que todos possamos ser livres juntos.

- Eu fui ensinado pela sociedade a ser machista e preciso de ajuda para enxergar caso eu esteja oprimindo alguém com as minhas atitudes.] d'autorisation éthique qui est identifié comme le lieu de parole des femmes, d'où émerge toute légitimation des actes de parole des hommes féministes dans leurs pratiques d'énonciation cautionnée. Cette énonciation est ancrée justement dans l'acceptation explicite par les locuteurs hommes de cet impératif éthique qui oblige à reconnaitre le primat de la parole des femmes pour dire ce qu'est le féminisme et qui peut de ce fait se dire féministe.

\section{Conclusions}

Une analyse des pratiques langagières nous a permis d'explorer la complexité des différentes configurations sociales et historiques de l'identité des hommes féministes sur les réseaux sociaux, ce qui nous a menées à décrire aussi bien les images discursives et la scène énonciative que les désignations développées au fil du discours. Nous sommes ainsi arrivées au point crucial où les espaces d'identification constituent une pluralité contradictoire de filiations historiques.

La dimension didactique que nous avons repérée dans l'énonciation des hommes féministes nous a mis en face des pratiques de soi constitutives de leur cyber-militance. L'autorisation éthique de ces pratiques repose sur le lieu de parole des femmes, à partir d'un mode de dire qui constitue une énonciation cautionnée.

\section{BIBLIOGRAPHY}

Authier-Revuz, Jacqueline. 1995. Ces mots qui ne vont pas de soi. Boucles réflexives et non-coïncidences du dire (Paris : Larousse).

Braidotti, Rosi, Jacqueline Aubenas \& Joëlle Meerstx. 1983. «Pour un féminisme critique ». Les Cahiers du GRIF 28 « D'amour et de raison », 36-44.

Foucault, Michel. 1984 « L'éthique du souci de soi comme pratique de la liberté » (entretien avec H. Becker, R. Fornet-Betancourt, A. Gomez-Müller, 20 janvier 1984), Revista internacional de filosofia 6, 99-116.

Guimarães, Eduardo. 2011. " Le marque du nom ». Astérion 8, en ligne : http:// asterion.revues.org/2074.

Argumentation et Analyse du Discours, 18 | 2017 
Jacquemart, Alban. 2015. Les hommes dans les mouvements féministes. Socio-histoire d'un engagement improbable (Rennes : Presses Universitaires de Rennes).

Orlandi, Eni (éd.). 2011[1990]. La Construction du Brésil. À propos des discours français sur la Découverte (Paris : L'Harmattan).

Paveau, Marie-Anne. 2013. Langage et morale. Une éthique des vertus discursives (Limoges : LambertLucas)

Paveau, Marie-Anne. 2015. «L'intégrité des corpus natifs en ligne. Une écologie postdualiste pour la théorie du discours ». Les Cahiers de Praxématique 59 « Corpus sensibles », 65-90.

Zoppi Fontana, Mónica. 2011. « Sujets (in)formels. Désignation dans les médias et subjectivation dans la différence », Astérion 8, en ligne : http:// asterion.revues.org/2058

\section{NOTES}

1.

http://www.larousse.fr/dictionnaires/francais/f\%c3\%a9ministe/33214? q=f\%c3\%a9ministe\#33137, consulté le 15 août 2016.

2. http://www.cnrtl.fr/definition/féministe, consulté le 15 août 2016.

3. https://houaiss.uol.com.br/pub/apps/www/v2-3/html/index.htm\#1, consulté le 15 bbbbaoût 2016.

4. https://houaiss.uol.com.br/pub/apps/www/v2-3/html/index.htm\#1, consulté le 15 août 2016

5. https://houaiss.uol.com.br/pub/apps/www/v2-3/html/index.htm\#1, consulté le 15 août 2016

6. https://houaiss.uol.com.br/pub/apps/www/v2-3/html/index.htm\#3, consulté le 15 août 2016

7. La matérialité (audio-)visuelle des textes numériques sur les réseaux sociaux participe aussi de cette construction, par la projection imaginaire d'une corporalité pour le moi énonciateur.

8. Les féminismes de quatrième génération possèdent des traits sémiotiques-textuels spécifiques et parfois innovants par rapport aux traditions antérieures, comme: la réflexivité, la mobilisation $\mathrm{du}$ corps, la présence du fait religieux et l'exploitation des univers numériques (Paveau et Pahud, 2017).

9. Il s'agit donc d'une marque d'hétérogénéité énonciative montrée (Authier-Rèvuz 1995).

10. Le mansplaining, terme entré il y a quelques années dans le vocabulaire des féministes anglophones et passé tel quel en français et dans d'autres langues, est un mot valise assemblant man et explaining. Il décrit le fait, pour un homme, d'expliquer à une femme comment elle doit vivre, agir, se comporter, etc., en particulier en ce qui concerne le féminisme.

11. La photo était prise par Nanni Rios à Porto Alegre, grande ville au sud du Brésil, pendant une Marcha das vadias [Slut Walk], en 2012.

12. Il y a des publications sur cet article dans les quatre communautés analysées.

13. Cette affiche, dont l'auteur est J. Howard Miller, datée 1943, était une publicité américaine pour promouvoir le travail des femmes dans les chaînes de montage de l'entreprise Westinghouse Electric Corporation. Le dessin est resté connu par le nom Rosie the Riveter et il a été réapproprié par les mouvements féministes pendant les années 1980, qui en ont fait un de leurs symboles le plus connu. Voir l'article de Marie-Anne Paveau qui détaille la dimension militante numérique de cette affiche, dans le présent numéro.

14. Guimarães (2002) distingue deux figures énonciatives pour décrire celui qui parle: le locuteur (ce qui est représenté dans l'énoncé comme responsable de l'énonciation) et le locuteur$x$, qui est défini comme le lieu social depuis lequel le locuteur parle et qui est constitué à l'intérieur de l'interdiscours par rapport aux positions discursives idéologiquement déterminées et aux instances institutionnelles dans une conjoncture donnée. 
15. Le masculinisme est un mouvement social récent qui a pour but de discuter et de renouveler les masculinités; la désignation masculiniste ou masculiste se réfère, ainsi, aux hommes qui militent contre le machisme sans se reconnaître comme féministes et qui prônent un rapport non conflictuel avec les mouvements des femmes. Au Brésil, il a un précédent daté 1985 : «Le manifeste masculiniste ", écrit par Marcelo Mario de Melo, militant de gauche. Ce manifeste circule encore sur les réseaux sociaux comme argument en faveur d'un mouvement propre aux hommes, où ils peuvent être des protagonistes, tout en refusant en même temps les pratiques machistes. Cette définition est un peu différente de celle qu'on devrait donner en France, où les mouvements masculinistes se définissent plus souvent comme de mouvements dénonçant l'oppression des hommes comme équivalente à celle des femmes, et dénonçant parfois des femmes comme des oppresseures.

\section{ABSTRACTS}

The presence of men in urban feminist events is common. This presence is disseminated by the media and especially through the circulation of pictures and posts in social networks. Blogs whose authors identify themselves as feminist / pro-feminism men multiply and produce controversial effects on feminist blogs. The controversy is centered on the political legitimacy of feminist activism by men. Our work brings an original approach to this subject by taking language as the object of analysis. We propose to examine the meanings produced by the resumption of feminist arguments by men and the argumentative operations staged to legitimize their enunciative position. Adjectivation and predication are clues that help us to understand what is at stake in this confrontation and to describe the different positions occupied by the militants. The corpus is composed of utterances (verbal and verbal-iconic) circulating in the activist blogosphere and in feminist and pro-feminist network communities.

La présence d'hommes dans les manifestations féministes urbaines est fréquente. Cette présence est diffusée par les médias et surtout par la circulation des photos et de posts dans les réseaux sociaux. Des blogs dont les auteurs s'identifient comme hommes féministes/pro-féminisme se multiplient et produisent des effets polémiques sur les blogs féministes. La controverse est centrée sur la légitimité politique de la militance féministe par des hommes. Notre travail porte sur ce sujet une approche originale qui prend le langage comme objet d'analyse. Nous nous proposons d'examiner les effets de sens produits par la reprise des arguments féministes par des hommes et les opérations argumentatives mises en scène pour légitimer leur position énonciative. L'adjectivation et la prédication sont des indices qui nous aident à comprendre les enjeux de cette confrontation et à décrire les différentes positions occupées par les militants. Le corpus est composé d'énoncés (verbaux et verbo-iconiques) qui circulent dans la blogosphère militante et dans les communautés féministes et pro-féministes des réseaux.

\section{INDEX}

Mots-clés: discours numérique, féminisme, hommes, nomination

Keywords: digital speech, feminism, men, nomination 
AUTHORS

MÓNICA GRACIELA ZOPPI FONTANA

UNICAMP/CNPQ (Campinas-São Paulo)

SHEILA ELIAS DE OLIVEIRA

UNICAMP/CNPQ (Campinas-São Paulo) 